European Journal of Sustainable Development Research

2019, 3(1), em0072

ISSN: 2542-4742

\title{
Comparing Virtual Learning, Classical Classroom Learning and Blended Learning
}

\author{
Javed Iqbal Suleri ${ }^{*}$, Anna Javed Suleri ${ }^{2}$ \\ ${ }^{1}$ NHL Stenden University of Applied Sciences, NETHERLANDS \\ ${ }^{2}$ Erasmus $M C$, NETHERLANDS
}

*Corresponding Author: jisuleri@yahoo.com

Citation: Suleri, J. I. and Suleri, A. J. (2019). Comparing Virtual Learning, Classical Classroom Learning and Blended Learning. European Journal of Sustainable Development Research, 3(1), em0072. https://doi.org/10.20897/ejosdr/3970

Published: February 6, 2019

\begin{abstract}
This reading aims to compare the role of Virtual Learning (VL), Classical Classroom Learning (CCL) and Blended Learning (VL\&CCL) in higher education. The literature review is presented in themes - Virtual Learning, Classical Classroom Learning and Blended learning. A quantitative method is applied in this study; data was obtained from 100 students from Erasmus University of Rotterdam by using an online questionnaire and convenient sampling. Questions were developed by the author and internal consistency and reliability were measured by Cronbach. The main findings illustrate that there was a significant relationship between gender and CCL, though, female respondents have more inclination towards CCL than their counterpart. Furthermore, VL has a significant relationship with CCL and Blended Learning. Thus, the intent of the learners to use blended learning in the future. Hence, this reading recommends educational institutions and educators to empower themselves with the use of technology, design their teaching methods as well as curriculum in such a way that the aim of that education is effective, efficient, convenient and approachable for all the learners at campuses as well as from distance.
\end{abstract}

Keywords: virtual learning, classical classroom learning, interactive learning, online learning, blended learning

\section{INTRODUCTION}

The $21^{\text {st }}$ century has brought our world together in different dimension. With a touch or a click we can have access to the world. Thanks to Information Communication Technology (ICT), information is everywhere and even around us. In these circumstances, trends are changing: innovation development is rapidly growing in every sector. In such an environment educational institutions and education sector are not lagging behind; educational institutions and educators are finding innovative ways to transform knowledge to our coming generation and generations to come. Therefore, virtual learning environments and blended learning have all become an accepted part of the classroom lexicon over the past few years (University of Oxford International Strategy Office, 2015). Furthermore, virtual learning depicts it to be a good alternative for classical classroom learning as it focuses on both classroom and virtual learning environment (Leask, 2004).

Educators and educational institutions have not limited themselves to the old classical classroom learning and have indulged themselves in innovative ways of delivering virtual or blended lessons. In addition, they are searching integrated ways to bring education to another level; how instructional power of digital innovation can leverage them. Project based learning or designed based education is the order of the day. Hence, on the one side this study is defining Virtual Learning (VL) as a supporting tool with multi-functions - information, communication, 
collaboration, convenience and freedom of learning. On the other side, defining Classical Classroom Learning (CCL) as the actions educator take to create a supportive academic environment for the learners (Evertson and Weinstein, 2006). For that reason, the focus of this study is to compare Virtual Learning (VL) and Classical Classroom Learning (CCL) and also delineate the learning process of the learners - if they prefer blended learning: combination of VL and CCL. According to Gray et al. (2010), blended learning may facilitate higher education to new student market through off-campus, offshore or distance education.

Our younger generation has been already demonstrating the impact of digital aura not only in education but in day to day life as well. There would be no harm to articulate that our youth has been completely synchronized by digital technologies - it has been fully assimilated feature of their lives (Green and Hannon, 2007). Furthermore, "Children has been establishing a relationship to knowledge gathering which has been alien to their parents and teachers" (Green and Hannon, 2007, p. 38). Seemingly, this transformation has serious effects for us in education.

Conventionally, education has been hampered by the safety, security and possible risk issues of commissioning virtual environments. Nonetheless, virtual learning should not be disregarded due to these dreads. On the one hand, for the further developments in virtual environments educational institutions should have the funds to find out new ways to manage the potential vulnerabilities. On the other hand, we have to accept virtual learning as having a collaborative relationship with education and educationalists.

Nonetheless, the exquisiteness of VL has its ability to create learning prospects and know-hows for the learners as well as for the educators that might never be able to be created in the CCL environment. Despite the fact that students and educators use VL environment for different reasons, the joint effort of using this has leveraged new projects. Therefore, in the same way technology is seeking to provide learners with collaborative skills while using virtual learning environment. Hence, the purpose of this reading is not only to compare a VL environment with a CCL environment but to find out the learning process of learners if we combine them - VL and CCL.

Based on abovementioned, this study will form the following problem statement:

\section{Comparing the Difference between Virtual Learning and Classical Classroom Learning in order to Enhance Blended Learning}

Considering the aforementioned facts, the subsequent hypotheses are used:

H1: What is the influence of virtual learning on the learners?

H2: What is the impact of virtual learning on classical classroom learning and on the learners?

H3: What is the influence of virtual learning on blended learning and on the learners?

\section{REVIEW OF LITERATURE}

The focus of this literature review is on the main themes of this study - Virtual Learning (VL), Classical Classroom Learning (CCL) and blended learning (combination of VL\&CCL).

\section{Virtual Learning (VL)}

Virtual learning depicts it to be a good alternative for CCL as it focuses on both classroom and virtual learning environment (Leask, 2004). In addition, ICT has brought new dimensions in higher education and has offered a range of opportunities to learners, educators and staff. It can be seen as an innovation facilitator - organisational, pedagogical and economic as well as an effective instrument for higher education. In the future, VL can be productively applied to meet the needs of the knowledge society (Boonen, 2010). Likewise, cross-border higher education has intensely challenged the framework of Massive Open Online Courses (MOOCs) which has taken the future of higher education to an entirely new level - VL (Rumbley and Altbach, 2016).

Nowadays educators are finding ways together with online class teaching and hence, technology is swaying oldfashioned CCL. Likewise, VL environments and blended learning have all become an accepted part of the classroom (University of Oxford International Strategy Office, 2015). In this reading, the VL working definition is demarcated as a supporting tool with multi-functions - information, communication, collaboration, convenience and freedom of learning. Thus, a good Software as a Service (SaaS) is the spine of VL which empowers communication between learner and educator. In fact, higher education is using virtual environments such as Electronic Learning Environment (ELE), Moodle or Blackboard for enabling information to the learners and staff. In reality, the foremost purpose of designing VL environment is an interaction between learner and educator.

Nonetheless, there is a hurdle; educational institutions have a restriction for users to access all platforms. Thanks to Microsoft SharePoint, documents can be shared with your peers and provide a possibility to the learners and educators to work synchronously on the same documents. Additionally, it has added functions - blogging, rating or tagging. Therefore, we could establish that technology is also supporting and developing innovative tools to facilitate and support blended education. 
Furthermore, VL gives us the capability to transfer insights in new ways. It is not like an old skin in a new jacket yet it is helping to teach the old learning material in new ways, likewise a new syllabus in new ways. In addition, VL is aiding and enhancing teaching. At the same time, it teaches intangible knowledge to learners. Similarly, it provides a possibility for educators to teach what they want. For that reason, if educational institutions empower educators and learners to have better access to the learning materials, it would not only be productive for educators and learners, but would be an added marketing value for the educational institution as well. Bearing this literature review in mind, this study discovers which opportunities the students are having towards virtual learning. Moreover, it is important to note whether these opportunities have an influence on learners' outcomes or not.

\section{Classical Classroom Learning (CCL)}

On the one hand, the definition of classical classroom learning is the actions educator take to create a supportive academic environment for the learners (Evertson and Weinstein, 2006). On the other hand, CCL is arranging the physical environment, establishing rules and procedures, maintaining students' attention to lessons and engagement in activities (Brophy, 2006, p. 17). In short, CCL is about two actors - a learner and an educator in a classroom. Classroom arrays the stage for CCL, consequently, in a disorganized classroom a very little academic learning can happen (Elias and Schwab, 2006, p. 309). Likewise, effective teaching and learning cannot take place in poorly managed classrooms (Jones and Jones, 2012; Van de Grift et al., 2011). For that reason, in CCL educator play a key role in shaping effective education (Hattie, 2009). Furthermore, in CCL the focus is on a learner problem, understanding and a role of an educator. Classroom learning also enables learners to discuss their comprehension of learning material with the educator as well as provide possibility to an educator to identify gaps in learners' knowledge and understanding.

In a classical school learning the program is built upon the idea of education through significant real world practices and examination. It may seem strange if the educator or learner incorporated virtual based education in a classroom. There are numerous benefits of using traditional instructional methods in a classroom. One of the strongest benefits of classroom learning is teaching students the skill of negotiation, collaboratively problem solving and to be mindful of their actions/impact on others.

Nevertheless, daily practice in education has transformed speedily. It is more and more characterized by learnercentred methodologies. A large stress is on students' metacognitive skills such as self-regulated learning strategies (Dignath et al., 2008) and cooperative learning (Wubbels et al., 2006). Furthermore, technology is finding its way into classrooms to a greater extent; for example, the use of interactive whiteboards, tablets, and laptops (Schussler et al., 2007). Based on the prior research findings, there is no harm to establish that both learners and educators have more inclination to find out more innovative ways to teach and learn. In such an environment, technology is playing a vital role in supporting teaching methods. As a result, education is increasingly blending classical and digital materials. Based on this literature review, this study discovers which opportunities the students are having towards classical classroom learning and whether they have an influence on learners outcomes or not.

\section{Blended Learning (VL\&CCL)}

The communication is both synchronous (VL) and asynchronous (CCL). As previous research proposed, there is a need to identify what VL features are being blended and appear to work in the CLL (Bash, 2015). In this reading, the focus is on the need to comprehend that blended learning is not only a technology; it is a mode of learning too - which is looking for a new combinations of VL and CCL from a powerful educational perception and it offers many meaningful and innovative opportunities for education.

As previous research indicates, traditional courses are becoming more of a hybrid course - combination of VL and CCL. Research is needed to identify what VL features are being blended and appear to work in the traditional classroom (Bash, 2015). Nonetheless, when we discuss distance learning courses, the content of the course delivered online (Allen and Seaman, 2004). However, by comparing elements for VL and CCL, incorporate technology has been referred to as hybrid of blended learning. As Boussemaere et al. (2006) define, because faceto-face meetings can never be totally replaced, VL methods should exist next to and in combination with CLL methods. Likewise, according to Gray et al. (2010), blending face-to-face and online learning may facilitate higher education to new student market through off-campus or offshore distance education. Nevertheless, learners in VL environment deserve to receive the same amount of feedback that would be present in the CLL environment. Furthermore, blended learning aligns better with the learner-centred approach and provide variety of ways of learning (Coelen, 2013). For VL, students need only a computer and an Internet connection at campus, home or elsewhere. Furthermore, VL learners have the choice to accept a virtual teaching method alongside CCL methods. Such learning activities are in fact a blended learning methodology. Keeping this literature review in mind, this study finds out the prospects the students are having towards blended learning and the influence on learners' outcomes. 


\section{CONCEPTUAL MODEL}

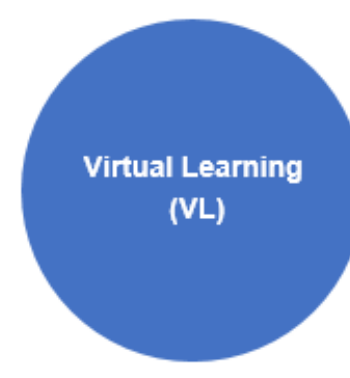

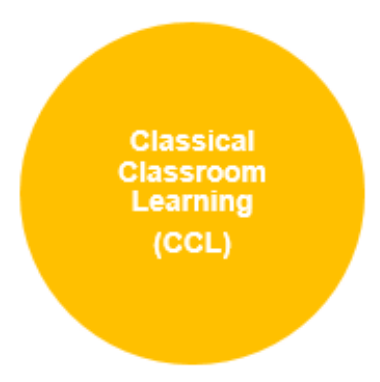
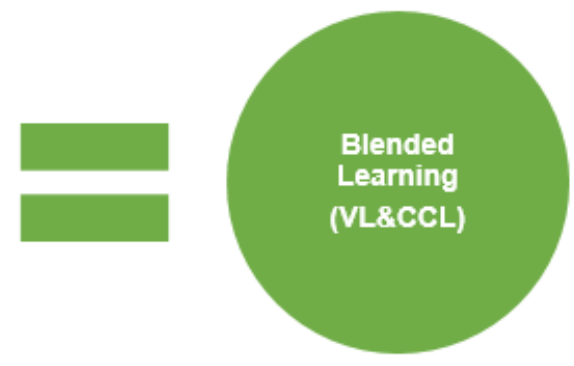

Blended Learning (Suleri, 2017)

\section{Method}

The quantitative survey method was applied to determine the role of virtual learning, classical classroom learning and blended learning in the higher education. A total of two hundred ten (210) students were contacted in this research. The online questionnaire was distributed to all of them and 100 respondents had filled it completely. The population size of this study was taken from Erasmus University Rotterdam (EUR); mainly from the faculty Medicine and Law. The respondents were divided in two groups; male 24 and female 76. Furthermore, an online questionnaire was the instrument used to gather data. The instrument included three parts $-\mathrm{A}, \mathrm{B}, \mathrm{C}$ and $\mathrm{D}$ as follows:

Part A contains questions regarding role of virtual learning, part B contains questions related to classical classroom learning, part $\mathrm{C}$ is comprised of questions addressing blended learning; whereas, at the end of the questionnaire in part $\mathrm{D}$, demographic features such as gender, age and institution name were measured with the aim to understand respondents' profile. To explore learners' inclination towards VL, CCL and blended learning, the author developed the questionnaire on the basis of the literature discussed in the literature review by using Likert scale ranging from strongly disagree (1) to strongly agree (5). The population of this research is mainly Erasmus University Rotterdam (EUR) medicine and law students. Convenient sampling method was chosen by spreading the online survey through different study cohort(s) by one of the authors.

\section{Core Findings}

A total of 100 students participated in this study, 24\% of the respondents were male and $76 \%$ female which indicates a real picture of Health and welfare of university under observation and in general all over The Netherlands (CBS report, 2016). First of all, descriptive analysis is performed, subsequently, to find out the reliability of data, Cronbach Alpha of variables such as virtual learning, classical classroom learning and blended learning were used to find out whether all the items in one scale were consistent. Subsequently, the ANOVA test was performed to measure male and female students' impact on virtual learning, classical classroom learning and blended learning. Finally, correlation was performed between virtual learning, classical classroom learning and blended learning.

\section{Virtual Learning (VL)}

The VL inclination of the learners were assessed with five different questions by using a Likert scale ranging from strongly disagree (1) to strongly agree (5) (Table 1). Grand mean and standard deviation of the fear is $(\mathrm{M}=$ 3.48, SD 0.69). Moreover, "Through virtual learning, I get freedom and convenience to make my own planning regarding learning" was the most important factor among learners $(M=4.07$, SD 0.79). In contrast, the lowest "Due to virtual learning, I find ample time to reflect critically on other students ideas" was the least important aspect among learners $(\mathrm{M}=2.74$, SD 0.88). This shows that students consider more freedom when they were arranging and managing their study and outcomes at their own pace. The Cronbach Alpha of virtual learning was $(\alpha=0.79)$ which is showing a good fit of all items to this construct. 
Table 1. Mean and standard deviation for VL $(\mathrm{N}=100)$

\begin{tabular}{lcc}
\hline & Mean & SD \\
\hline Through virtual learning, I get freedom and convenience to make my own planning regarding learning. & 4.07 & 0.79 \\
\hline Virtual learning is not restricting my mobility and providing me overall access to follow learning materials. & 3.88 & 0.92 \\
\hline Virtual learning gives me enough time and opportunity to think critically about my ideas and about learning material. & 3.58 & 0.97 \\
\hline A virtual learning environment is providing me satisfaction and fulfilling my learning appetite. & 3.17 & 1.11 \\
\hline Due to virtual learning, I find ample time to reflect critically on other students ideas & 2.74 & 0.88 \\
\hline Cronbach's Alpha $(\alpha=0.79) ;$ Grand mean $=3.48$, SD $=0.69$ & \\
\hline
\end{tabular}

Table 2. Mean and standard deviation for CCL $(\mathrm{N}=100)$

\begin{tabular}{lcc}
\hline & Mean & SD \\
\hline Classroom learning facilitates me to interact with other students as well as the lecturer. & 4.22 & 0.85 \\
\hline $\begin{array}{l}\text { Classroom learning provides me with the opportunity to be creative and brainstorm diverse ideas to solve problems } \\
\text { in the classroom. }\end{array}$ & 3.50 & 0.94 \\
\hline Classroom learning demonstrates my ability to define concepts as part of the material covered. & 3.53 & 0.69 \\
\hline Classroom learning enables me to understand concepts explained in the classroom. & 3.85 & 0.74 \\
\hline Classroom learning gives me the opportunity to share knowledge with my peers. & 3.82 & 0.83 \\
\hline Cronbach's Alpha $(\alpha=0.72)$; Grand mean $=3.66$, SD $=0.56$ & \\
\hline
\end{tabular}

Table 3. Mean and standard deviation for Blended Learning $(\mathrm{N}=100)$

\begin{tabular}{lcc}
\hline & Mean & SD \\
\hline I think virtual learning is efficient if institutions are providing technical support to both educator and learner. & 3.99 & 0.86 \\
\hline I think institutions should empower educators as well as learners regarding digital skills. & 4.06 & 0.68 \\
\hline It would be efficient if learning material is available in the classroom as well as a virtual environment. & 4.47 & 0.69 \\
\hline $\begin{array}{l}\text { I think a combination of virtual learning and classroom learning enhances professional goal achievement } \\
\text { of both learner and educator. }\end{array}$ & 4.43 & 0.74 \\
\hline Cronbach 's Alpha $(\alpha=0.75)$; Grand mean $=4.23$, SD $=0.56$ & \\
\hline
\end{tabular}

\section{Classical Classroom Learning (CCL)}

CCL among learners were assessed with six different questions using a Likert scale ranging from strongly disagree (1) to strongly agree (5) (Table 2). Grand mean and standard deviation of the CCL was (M = 3.66, SD 0.56). Moreover, "Classroom learning facilitates me to interact with other students as well as the lecturer" was the most important factor among learners $(\mathrm{M}=4.22$, SD 0.85). In contrast, the lowest "Classroom learning gives me the opportunity to discuss my study development with the educator" was the least important aspect among learners ( $\mathrm{M}=3.02$, SD 1.08). On the one hand it indicates that the physical presence of the student in the classroom has marginal effect regarding their study development. On the other hand this shows that learners really appreciate physical interaction with the educator as well as with their peers. The Cronbach Alpha of virtual learning was $(\alpha=0.72)$ which indicates a high level of internal consistency of all items to this construct.

\section{Blended Learning (VL\&CCL)}

As shown in Table 3, respondents were asked four queries about blended learning - combination of VL and CCL using a Likert scale ranging from disagree (1) to agree (5). Grand mean and standard deviation of the time is $(\mathrm{M}=4.23$, SD 0.56). In addition, "It would be efficient if learning material is available in the classroom as well as a virtual environment." (M = 4.47, SD 0.69) and "I think a combination of virtual learning and classroom learning enhances professional goal achievement of both learner and educator" $(\mathrm{M}=4.43, \mathrm{SD} 0.74)$ were the most important elements among learners. Whereas, "I think virtual learning is efficient if institutions are providing technical support to both educator and learner" was a slightly less important feature among learners $(\mathrm{M}=3.99$, SD 0.86). This demonstrates that learners were craving for blended working environments. The Cronbach Alpha of virtual learning was $(\alpha=0.75)$ which indicates a high level of internal consistency of all items to this construct.

\section{Female Learners have more Inclination toward CCL than VL and Blended Learning.}

Table 4 shows a significant difference of CCL between gender and significance and was tested at the $\mathrm{p}<0.05$ level for all computation. Differentiating between male and female, the classical classroom learning for men $(\mathrm{M}=$ $3.43, \mathrm{SD}=0.71)$ were a tad lower than for women $(\mathrm{M}=3.73, \mathrm{~S} . \mathrm{D} .=0.48),[\mathrm{F}(1,98)=5.43, \mathrm{p}=0.02]$. However, male and female respondents have equally inclination towards virtual learning and blended learning, even though the mean of blended learning was realistically high and indicates respondents' preferences.

\section{Correlation Analysis}

The correlation analysis was directed to find out the linear relationship between two variables. Moreover, in this section, the relationship between VL, CCL and blended learning were analyzed by Pearson's correlation 
Table 4. Comparing Gender with learning process VL, CCL and VL\&CCL $(\mathrm{N}=100)$

\begin{tabular}{|c|c|c|c|c|c|}
\hline & Gender & $\mathbf{N}$ & Mean & SD. & $\mathbf{F}$ \\
\hline \multirow[t]{2}{*}{$\mathrm{VL}$} & Male & 24 & 3.52 & 0.76 & $\mathrm{~F}(1,98)=0.05, \mathrm{p}=0.82$ \\
\hline & Female & 76 & 3.48 & 0.67 & \\
\hline \multirow[t]{2}{*}{ CCL } & Male & 24 & 3.43 & 0.71 & $\mathrm{~F}(1,98)=5.43, \mathrm{p}=0.02$ \\
\hline & Female & 76 & 3.73 & 0.48 & \\
\hline \multirow[t]{2}{*}{ VL \& CCL } & Male & 24 & 4.22 & 0.59 & $F(1,98)=0.00, p=0.93$ \\
\hline & Female & 76 & 4.24 & 0.56 & \\
\hline
\end{tabular}

$\mathrm{P}<0.05$

Table 5. Correlation and reliabilities of study variable $(\mathrm{N}=100)$

\begin{tabular}{lll}
\hline Variable & $\mathbf{1}$ & $\mathbf{2}$ \\
\hline $1 . \quad \mathrm{VL}$ & 1.00 & $\mathbf{3}$ \\
\hline $2 . \quad \mathrm{CCL}$ & $\mathbf{0 . 0 2 *}$ & 1.00 \\
\hline $3 . \quad \mathrm{VL} \& \mathrm{CCL})$ & $\mathbf{0 . 0 0 * *}$ & 0.37 \\
\hline Note: ${ }^{*} \mathrm{p}<0.05 ; \mathrm{p}^{* *}<0.01$, Cronbach alphas for scaled variables: VL $=0.79$, CCL $=0.72$, and Blended learning $(\mathrm{VL} \&$ CCL) $=0.75$
\end{tabular}

coefficient. Table 5 specifies correlation, reliability and Cronbach alphas among scaled variables such as VL, CCL and blended learning (VL\&CCL). Besides, Cronbach Alpha is an indicator to find out whether all items in one scale are consistent and values above 0.70 is acceptable. This section highlights only the significant correlation. First of all, Table 5 designates that there is a significant relation between VL and CLL $(r=0.229$, $\mathrm{p}=0.02)$ where the significant level is $\mathrm{p}<0.05$ which means if students will have choice, they will prefer to combine classical classroom learning environment with virtual learning. Secondly, VL has significant relation at $\mathrm{p}<0.001$ with VL\&CLL $(\mathrm{r}=0.565, \mathrm{p}=0.001)$ which predicts that students scoring more on $\mathrm{VL}$ will have more inclination towards blended learning. Hence, looking at the outcomes of this study, it can be established that blended learning can play an important role in higher education and can be used as an effective tool in order to facilitate learners in their learning process.

\section{DISCUSSIONS}

\section{What is the Effect of Virtual Learning on the Learners?}

The first objective of this study was to examine the stimulus of virtual learning on the learners. The results revealed that VL was not a significant element to influence learner learning process. Nonetheless, the response to the following item: 'through virtual learning, I get freedom and convenience to make my own planning regarding learning' shows learners to be open for adopting VL for their learning process and supporting the forthcoming of VL in the higher education (Rumley and Altbach, 2016). Likewise, virtual learning has become an accepted part of classroom learning (University of Oxford International Strategy Office, 2015). In short, this study discovered a preference of the learners toward VL was tad less as compare to CCL at higher education. Hence, this hypothesis was not fully supported.

\section{What is the Impact of Virtual Learning on Classical Classroom Learning and on the Learners?}

The second objective of this study was to scrutinize the effect of classical classroom learning on the learners. As previous researchers stated, classical classroom learning was about two actors - a learner and an educator in a classroom. Furthermore, a classroom displays the stage for CCL, consequently, in a disorganized classroom a very little academic learning can happen (Elias and Schwab, 2006, p. 309). However, results of this study divulge that VL has a significant relationship with CCL and therefore learners would like to combine of VL and CLL in order to get better learning progression. Notwithstanding, there is a need to identify what virtual learning features are being blended and appear to work in the classical classroom learning (Bash, 2015). Hence, VL significant relationship in the direction CCL means - a clear preference toward blended learning at higher education. For that reason, this hypothesis was fully supported.

\section{What is the Impact of Virtual Learning on Blended Learning and on the Learners?}

The third objective of this study was to analyze the impact of blended learning on the learners. The outcome of this reading disclosed virtual learning as having a significant relationship with blended learning which predicts that students scoring more on VL will have more inclination towards blended learning. This is in line with the previous research that proposed, blending face-to-face and online learning may facilitate higher education to new student market through off-campus or offshore distance education (Gray et al., 2010). Likewise, as Coelen (2013) endorsed, blended learning aligns better with the learner-centred approach and provides variety of ways of learning. 
Hence, the conclusion of this study has established that students' inclination is towards blended forms of education. In view of that, this hypotheses is fully supported.

\section{CONCLUSION AND RECOMMENDATION}

The purpose of this study was not only to compare a VL environment with a CCL environment but to find out the learners' learning progression if we combine them - VL and CCL (blended learning). The outcome of this reading revealed on the one hand, preference of learners toward VL was a tad less than CCL. On the other hand, VL was significantly related to CCL means - a clear preference toward blended learning at higher education. Hence this study strongly recommends blended learning in the higher education. Moreover, educational institutions have to encourage virtual environment for its learners and develop programmes which are available in a classroom as well as in virtual environment.

Henceforth, this reading recommends educational institutions and educators to empower themselves with the use of technology and design their teaching methods and curriculum in such way that the education provided is more effective, efficient, convenient and approachable for all the learners at campuses as well as from distance.

This study was only carried out within the medicine and law department at Erasmus university and was exclusively allocated for virtual learning, classical classroom learning and blended; however, educators did not take part in this study. In order to find out the opinion of the educators information could be gathered from educators as well. Above all, a similar study could be carried out in a University of Applied Sciences. The findings from Applied Universities might indicate similar or absolutely different results which can be used to introduce blended learning and design their curriculum accordingly.

\section{REFERENCES}

Bash, E. (2015). Evaluating Distance Education. PhD Proposal. http://doi.org/10.1017/CBO9781107415324.004 Boonen, A. M. (2010). The Role of Virtual Mobility on Higher Education Institutions, Virtual Mobility on Higher Education institutions Published, Centro Enseñanzas Virtuales. University of Granada.

Boussemaere, M., Rajagopal, K. and Beeck, I. Op De. (2006). European Cooperation in Education through Virtual Mobility.

Brophy, J. (2006). History of Research on Classroom Management. In C. M. Evertson \& C. S. Weinstein (Eds.), Handbook of classroom management. Research, practice, and contemporary issues (pp.17-43). Malwah, NJ: Lawrence Erlbaum Associates.

CBS report. (2016). Available at: http://download.cbs.nl/pdf/2016-the-netherlands-on-the-european-scale2016.pdf

Coelen, R. J. (2013). The Internationalisation of Higher Education, inaugural lecture (November, 2013). Stenden University of Applied Sciences.

Dignath, C., Buettner, G. and Langfeldt, H. (2008). How can primary school students learn self-regulated learning strategies most effectively? A meta-analysis on self-regulation training programmes. Educational Research Review, 3, 101-129. https://doi.org/10.1016/j.edurev.2008.02.003

Elias, M. J. and Schwab, Y. (2006). From compliance to responsibility: Social and Emotional Learning and classroom management. In: C. M. Evertson \& C. S. Weinstein (Eds.), Handbook of classroom management. Research, practice, and contemporary issues (pp. 309-341). New York/London: Lawrence Erlbaum Associates.

Evertson, C. M. and Weinstein, C. S. (Eds.) (2006). Handbook of classroom management. Research, practice, and contemporary issues. Mahwah, NJ: Larence Erlbaum Associates, Inc.

Gray, K., Chang, S. and Kennedy, G. (2010). Use of social web technologies by international and domestic undergraduate students: implications for internationalising learning and teaching in Australian universities. Technology, Pedagogy \& Education, 19(1), 31-46. http://doi.org/10.1080/14759390903579208

Green, H. and Hannon, C. (2007). Their Space: Education for a digital generation. Available at: http://www.demos.co.uk/files/Their\%20space \%20-020web.pdf (Accessed 4 September 2007)

Hattie, J. (2009). Visible learning: A synthesis of over 800 meta-analyses relating to achievement. London; New York: Routledge.

Jones, V. F. and Jones, L. S. (2012). Comprehensive classroom management, creating communities of support and solving problems (10th ed). Upper Saddle River, NJ: Pearson.

Leask, B. (2004). Internationalisation 0utcomes for all students using information and communication technologies (ICTs). Journal of Studies in International Education, 8(4), 336-351. http:// doi.org/10.1177/1028315303261778

Rumbley, L. E. and Altbach, P. G. (2016). The local and the global in higher education internationalization, Jones, E. et al. (eds.), Global and local internationalization, Rotterdam: Sense publishers. 
Schussler, D. L., Poole, I. R., Whitlock, T. W. and Evertson, C. M. (2007). Layers and links: Learning to juggle "one more thing" in the classroom. Teaching and Teacher Education, 23, $572-585$. https://doi.org/10.1016/j.tate.2007.01.016

University of Oxford International Strategy Office. (2015). International Trends in Higher Education, University of Oxford. Available at: http://www.mendeley.com/catalog/international-trends-higher-education-1 ISSN: 1781905754

Van de Grift, W., Van der Wal, M. and Torenbeek, M. (2011). Ontwikkeling in de pedagogisch didactische vaardigheid van leraren in het basisonderwijs [Development in teaching skills]. Pedagogische Studiën, 88, 416-432.

Wubbels, T., Den Brok, P., Veldman, I. and Van Tartwijk, J. (2006). Leraar-leerlingrelaties en klassenmanagement in het hedendaagse onderwijs [Teacher-student relationships and classroom management in present-day education]. In R. Klarus and W. Wardekker (Eds.), Wat is goed onderwijs: Bijdragen vanuit de pedagogiek (pp. 121-141). Den Haag: Boom Lemma Uitgevers. 